doing well at work may reflect some degree of bias in selecting day-patients from those presenting with work problems. It may also be suggested that the larger number of respondents, and the significantly smaller number of spoilt or incompletely returned forms from the day-patient sample, point towards a greater involvement in, and commitment to, their past treatment, whereas for out-patients commitment may be more tenuous. Though the results may have been different had a comparable sample of out-patients responded adequately, it is doubtful whether any firm opinions could have been formulated based on such relatively crude measurements. Only a much more detailed, sophisticated investigation, designed to elicit the finer qualitative responses to the two types of approach and their meaning for the patient, can give an answer to whether, in terms of clinical and social gains (rather than in terms of management) patients are at an advantage in day care.

SUSANNE Shapar.

Day Department, Crumpsall Hospital, Manchester 8.

REFERENCES

1. Ferguson, R. S. (1968). B. med. 7., i, 119.

2. Farndale, W. A. J. (1967). New Aspects of the Mental Health Services. Oxford, Pergamon.

3. O'Gorman, G. (1968). Modern Trends in Mental Health and Subnormality. London. Butcerworth.

4. Ferguson, R. S. Personal Communication.

\section{THE LESBIAN PERSONALITY}

\section{DeAr Sir,}

In preparation for a lecture I have just re-read June Hopkins' paper (Journal, December 1969) and my suspicion that her description of personality was simply that of a lesbian who might volunteer for a survey was rekindled. The sample studied was doubly self-selected, latterly by volunteering for study and formerly by joining an active minority group. The author at one stage in her paper recognizes this, but refers on the basis of her study to the average lesbian as being independent. From the paper one could construct the hypothesis that lesbians who are the dominant partners in a relationship are more likely to join active minority groups and more likely to show the traits described in the summary of the paper. Would Sister George have allowed her Alice to volunteer for the survey or even to join a wider group of lesbians?

One does not make a sample more representative of its group by comparing it with controls. It is doubtful whether one can even describe the groups as matched for, although certain factors have been paired, the controls were presumably also volunteers who may have had entirely different motives for volunteering. There is no indication that they belong to other active minority groups. Finally, the description of the personality traits found may be those applicable to a situation in the lesbian partnership and may not be related to status in the wider world.

Highcroft Hospital,

B. H. Fookes.

\section{Erdington,}

Birmingham 23.

Dear Sir,

In the last paragraph of his letter, Dr. Fookes' comment 'One does not make a sample more representative of its group by comparing it with controls' is true. However, he then suggests that the motives of the controls were probably different from those of the subjects. I fail to comprehend the significance of such a statement. I would be very surprised to find 'the motives' of any control group in a study of this kind being queried prior to their selection as subjects. It is difficult to believe they are.

Earlier in his letter he has said, 'From the paper one could construct the hypothesis that lesbians who are the dominant partners in a relationship ... are more likely to show the traits described in the summary ... '. Dr. Fookes has obviously jumped to the conclusion that the majority of the lesbians in the investigation were the dominant partners. Such an assumption is unwarranted, if it is based on my paper. The majority of the 105 lesbians who originally participated in the research came in partner teams to be tested. The 24 selected could just as easily have been 'submissive' partners as 'dominant' ones. There is no way to distinguish, as they were selected explicitly because they most nearly matched the controls in age, intelligence and profession. In any case, I feel that strict role-typing (dominant and submissive) has no real place in the discussion of relationships generally. Roles in relationships change constantly, depending on situations, and we tend to lose sight of this fact when we stereotype the individuals concerned by placing labels on them.

My paper is open to the criticism that I have compared unmarried women with married women. My reason for doing this is that I attempted to ward off any speculation of those women claiming to be heterosexual by using facts, i.e., husband and children, as objective support of their subjective Kinsey ratings. I feared that unmarried heterosexual women might be suspect, particularly if their results (perhaps 
due to their leading lives relatively independent of males) had been similar to those of the lesbians. In any case, until marital status has been controlled as well as other factors, the results of my research, although interesting, may prove little. It is my hope to write a much more comprehensive paper based on a much larger number of subjects, which will be considerably more definitive concerning the lesbian personality than was possible in the present study.

North Riding College of Education, JUNE H. HOPKINS.

Filey Road,

Scarborough.

\section{PATIENTS' PERGEPTION OF HIDDEN FIGURES}

Dear Sir,

May I refer Messrs. Crookes and Hutt, whose articles entitled 'Perception of Hidden Figures by Neurotic and Schizophrenic Patients' appeared in the March issue of the Fournal (p. 335), to the work I have done in this field $(1,2)$ ? I too found significant differences between the performances by schizophrenic and neurotic patients on the Gottschaldt figures. When the effect of intelligence on these performances was partialled out, however, the differences disappeared ( 1 ). Moreover, a factoranalytic study which was undertaken later confirmed that the (untimed) Gottschaldt Figures Test is an almost pure measure of general intelligence (2).

Sunnybrook Hospital,

2075 Bayview Avenue,

Toronto 12, Ontario, Canada.

(1) Romerey, D. M. (1967). Aspects of Cognitive Dysfunction in Nuclear Schizophrenics and their Parents and Siblings. Unpublished Ph.D. thesis, University of Newcastle Library.

(2) - (1969). 'The validity of certain tests of overinclusion'. Brit. J. Psychiat., 115, 591-2.

\section{PSYCHOTHERAPY WITH FAILURES OF PSYCHOANALYSIS}

Dear Sir,

The paper by M. Schmideberg (1 16: February, 1970, pp. 195-200) clarifies the question we should be asking when we embark on psychoanalysis or other long-term psychotherapeutic endeavours. The patients in such situations are chronic, or will become so during the course of prolonged therapy, and are suffering from some degree of defect or disability. It follows that the medical model for the rehabilitation of the chronic patient may thereby be applicable, and such principles as the development of motivation, the assisting of the patient in acquiring new skills in work or living, and the structuring of a program of graduated steps in the return to full functioning are to be considered in the treatment. The chronic patient, be he tubercular or neurasthenic, has much the same problem in finding his way back to full community participation.

If we accept this view that chronicity is one of the essential features of the patient commonly seen in long-term psychotherapy, we must then ask what is the contribution of psychotherapy to the rehabilitation of the chronic psychiatric patient? Rehabilitation is invariably a complex process involving many modalities, and a total program that will vary from phase to phase with the patient's progress through his rehabilitation. It follows, then, that psychotherapy as a total approach to the chronic patient cannot but be inadequate. The psychotherapist who sits in a room alone with the chronic patient and engages in a verbal exchange is of little assistance to the patient who needs practice in developing new life skills. The psychotherapist's consultation room is hardly an all-purpose laboratory for dealing with daily life problems. Furthermore, the passiveappearing psychotherapist is a particularly poor role model to the patient in his search for new and useful identifications. To the psychotherapy patient, the psychotherapist is the least active of workers. He appears to do nothing and to relate to no one. He does not appear to 'work'.

I would submit that when we have identified a chronic patient in need of psychiatric rehabilitation, such a program should never be limited to psychotherapy, and psychotherapy should always be combined with other rehabilitative techniques. For the chronic patient coming from the middle and upper social classes, the practice in verbal techniques afforded by psychotherapy is not usually the necessary element in his rehabilitation. Rather, participation in meaningful vocational and social situations is much more essential. In contrast, patients drawn from the lower classes may be defective in the verbal skills required and impartable from psychotherapy. Hence, we might conclude that psychotherapy is of more critical importance and potential value in relation to chronic patients drawn from the lower classes than to those from the upper and middle classes. This, of course, is in marked contrast to the practices and preferences of the psychotherapist as a practising professional.

Another consideration in the development of a program for the rehabilitation of the chronic psychiatric patient pertains to the use of the paraprofessional. This type of mental health technician or indigenous 